Int. J. Dev. Biol. 57: 365-373 (2013)

doi: $10.1387 / \mathrm{ijdb} .120227 \mathrm{hl}$

\title{
Trans-2-phenylcyclopropylamine regulates zebrafish lateral line neuromast development mediated by depression of LSD1 activity
}

\author{
YINGZI HE 1,2,\#, HUIQIAN YU2,\#, SHAN SUN² ${ }^{2}$ YUNFENG WANG ${ }^{1}$, \\ LIMAN LIU' ${ }^{1}$, ZHENGYI CHEN ${ }^{3}$ and HUAWEI LI*,1,2
}

\begin{abstract}
${ }^{1}$ Institutes of Biomedical Sciences of Fudan University, Shanghai, China, ${ }^{2}$ Department of Otolaryngology, Affiliated Eye and ENT hospital of Fudan University, Shanghai, China and ${ }^{3}$ Department of Otolaryngology and Program in Neuroscience,

Harvard Medical School and Eaton Peabody Laboratory, Massachusetts Eye and Ear Infirmary, Boston, MA, USA
\end{abstract}

\begin{abstract}
The zebrafish mechanosensory lateral line (LL) is a model system for the study of hair cell development, survival and regeneration. Recently, histone modifications have attracted a considerable amount of interest because of their indispensable roles in various kinds of cellular processes including differentiation, proliferation, apoptosis and function. Lysine specific demethylase 1 (LSD1) is an important enzyme that regulates histone methylation. As a transcriptional regulator, this enzyme has broad functional activities and is involved in many biological processes. However, the effects of LSD1 on the early development of zebrafish sensory system have not been fully elucidated. Here, we have found that pharmacological inhibition of LSD1 with the monoamine oxidase (MAO) inhibitor trans-2-phenylcyclopropylamine (referred to as 2-PCPA) reduced the numbers of both sensory hair cells and supporting cells of neuromasts during zebrafish development. Our results showed that the treatment of zebrafish larvae with 2-PCPA caused accumulation of histone methylation and suppressed proliferation of neuromast cells. Finally, acridine orange staining assay demonstrated that 2-PCPA treatment at high concentrations induced an enhancement of cellular apoptosis within neuromasts. Taken together, these results indicate that LSD1 demethylase activity is required for neuromast development in zebrafish larvae.
\end{abstract}

KEY WORDS: hair cell, LSD1, neuromast, trans-2-phenylcyclopropylamine, zebrafish

\section{Introduction}

The zebrafish lateral line is a mechanosensory system, which is dedicated to detect directional water currents and thereby facilitates prey detection or predator avoidance (Montgomery et al., 2000). The lateral line system comprises a series of rosette-like sense organs called neuromasts, which appear in stereotypic locations on the surface of the head and body (Dambly-Chaudiere et al., 2003). Based on the location of composite neuromasts, the lateral line system can be divided into two subgroups: the neuromasts arranged on the head form the anterior lateral line (ALL), while the neuromasts located on the body and tail form the posterior lateral line (PLL). Mature neuromasts are composed of central hair cells (HCs) and peripheral supporting cells (SCs). HCs in the lateral line organ are morphologically, developmentally, and functionally similar to those in mammalian inner ear (Haddon and Lewis, 1996; Nicolson, 2005; Raible and Kruse, 2000). In addition, neuromasts are located on the surface of zebrafish, making the $\mathrm{HCs}$ quite accessible to fluorescent dyes, such as FM1-43. This accessibility of HCs in lateral line neuromasts hence facilitates easier experimental setup for the investigation of molecular and cellular

\footnotetext{
Abbreviations used in this paper: 2-PCPA, trans-2-phenylcyclopropylamine; ALL, anterior lateral line; $\mathrm{AO}$, acridine orange; BrdU, bromodeoxyuridine; $\mathrm{Cdk}$, cyclin-dependent kinase; CKI, cyclin-dependent kinases inhibitor; dpf, days post-fertilization; HC, hair cell; LL, lateral line; LSD 1, lysine specific demethylase 1; MAO, monoamine oxidase; MS-222, 3-aminobenzoic acid ethyl ester, methanesolfonate salt; PFA, paraformaldehyde; PLL, posterior lateral line; SC, supporting cell.
}

\footnotetext{
*Address correspondence to: Huawei Li. Department of Otolaryngology, EENT Hospital, Fudan University, Shanghai, 200031, China. Tel: +86-21-6437-7134. Fax: +86-21-6437-7151 E-mail: lihuawei09611@163.com

\#Note: These authors contributed equally to this work.
} 
mechanisms which are crucial for hair cell development, death, regeneration, and protection. The zebrafish lateral line system is also a popular model for HCs toxicology studies (Hill et al., 2005). Like mammalian hair cells, the lateral line HCs have been shown to be vulnerable to ototoxic compounds including aminoglycoside antibiotics and cisplatin in a dose-dependent fashion (Chiu et al., 2008; Harris et al., 2003; Ou et al., 2007; Van Trump et al., 2010). Zebrafish lateral line system has been used as chemical screens for assessing ototoxic and potentially otoprotective compounds (Owens et al., 2008; Ton and Parng, 2005).

The lateral line organ of zebrafish has also been used to study collective cell migration and cell polarity, as well as HCs biology associated with human hearing disorders including development, death, and regeneration at the embryonic stages. Recently, many works have focused on the function of various signaling pathways such as chemokine, Wnt, FGF, and Notch in the development of the lateral line system (Aman et al., 2011; Aman and Piotrowski, 2008; Chitnis et al., 2012; Dambly-Chaudiere et al., 2007; Ghysen and Dambly-Chaudiere, 2007; Lecaudey et al., 2008; Nechiporuk and Raible, 2008). The morphogenesis, survival, differentiation, regeneration, and function of the mechanosensory cells have also been shown to depend on coordinated and strictly regulated genes expression (Fritzsch etal., 2006; Kelley, 2006). However, the epigenetic mechanism which is crucial in both eukaryotic gene expression and formation of $\mathrm{HC}$ during neuromast maturation in PLL remains elusive. Histone modifications, including methylation, acetylation, phosphorylation, ubiquitination, and sumoylation, impact chromatin structure and consequently affect gene transcription (Berger, 2002; Jenuwein and Allis, 2001; Kouzarides, 2007). Recently, chromatin remodeling and transcriptional regulation via posttranslational histone modification attract a considerable amount of attention due to their influences in various kinds of, especially hearing related, biological processes (Provenzano and Domann, 2007).

As one important modification, histone methylation plays a pivotal role in a variety of cell biological processes. It is regulated by histone methyltransferases and demethylases (Kooistra and Helin, 2012; Rice and Allis, 2001; Zhang and Reinberg, 2001). Unlike histone acetylation, which is generally associated with transcriptional activation (Roth et al., 2001), histone methylation can post-transcriptionally either activate or repress downstream proteins, depending upon the sites of modifications (Martin and Zhang, 2005; Zhang and Reinberg, 2001). As the first discovered histone lysine demethylase, Lysine-specific demethylase 1 (LSD1, also known as AOF2, BHC110 or KDM1) belongs to the amine oxidase family. By modulating the histone methylation with a removal of the methyl groups from mono- and di-methylated histone H3K4 or H3K9, LSD1 is capable of repressing or activating the target genes (Metzger et al., 2005; Shi et al., 2004). LSD1 has broad functional activities in regulatory programs and is required for normal embryonic development, such as the development of hematopoietic system and neural system (Hu et al., 2009; Jie et al., 2009; Wang et al., 2007). A recent research also reported that LSD1 was required for cell proliferation and its defect led to a partial $\mathrm{G}_{2} / \mathrm{M}$ arrest (Scoumanne and Chen, 2007). However, the specific function of LSD1 in HC development is still unknown. Several monoamine oxidase (MAO) inhibitors, including the clinically used antidepressant trans-2-phenylcyclopropy-lamine (2-PCPA), are effective in inhibiting LSD1 in vivo (Lohse et al., 2011; Schmidt and McCafferty, 2007; Yang et al., 2007). Thus, these chemical inhibitors can serve as a potential resource for understanding the influence of LSD1 in HC development, and may be useful to investigate hearing-related behaviors.

In this study, we investigate the role of LSD1-mediated demethylation in the development of neuromasts in the lateral line system of zebrafish. Our results suggest that 2-PCPA treatment hampers neuromast development with a number reduction in both hair cells and supporting cells compared to the controls, due to the inhibition of progenitor cell proliferation. This study suggests that LSD1 activity is involved in the development of the lateral line system in zebrafish larvae.

\section{Results}

\section{Fewer neuromast hair cells are developed by exposure to 2-PCPA}

In order to determine the possible effects of 2-PCPAon zebrafish lateral line neuromast development, we added 2-PCPA to fish water at 3 days post fertilization ( $\mathrm{dpf}$ ) zebrafish larvae, and observed the differentiation of neuromast after 2 days of exposure. We found that the neuromast size was reduced in the presence of inhibitor as compared to the controls (Fig. 1). In larvae treated with $75 \mu \mathrm{M}$ $2-P C P A$, a neuromast harbored $39 \pm 0.45$ cells ( $n=26$ fish). As a comparison, a neuromast contained $47.6 \pm 0.58$ cells $(n=20$ fish; Student's t-test, $t=12.019$ with 44 degrees of freedom; $P=1.716 \mathrm{E}-015$ ) in control larvae. To confirm whether the neuromast development defect was actually induced by the inhibition of LSD1 demethylase activity, we examined the level of histone H3K4 methylation using fluorescent immunostaining and western bloting (Fig. 1 A-C). Our data showed that the histone methylation level in 2-PCPA treated group was significantly increased as compared to the controls. This observation provides an indication that the neuromast development defect induced by the presence of 2-PCPA could be a direct consequence of LSD1 inhibition.

To further analyze the effects of 2-PCPA on neuromast hair cells development, we incubated 5 dpf larvae with a vital dye FM1-43FX to label functional (mechanotransductively active) hair cells (Gale et al., 2001; Meyers et al., 2003) and counted the cell number. Fig. 1D and $1 \mathrm{E}$ show representative images of FM1-43FX labeled hair cells in neuromasts from a control specimen (Fig. 1D) and a specimen exposed to $75 \mu \mathrm{M}$ 2-PCPA for 2 days (Fig. 1E). From these images, we found that 2-PCPAtreatment caused a significant number reduction in FM1-43FX labeled hair cells in neuromasts. Indeed, as shown in Fig. 1 l, only $5.6 \pm 0.26$ stained hair cells were contained in a neuromast in $75 \mu \mathrm{M}$ 2-PCPA treated larvae $(n=18$ fish), in clear contrast to $8.5 \pm 0.17$ hair cells per neuromast in control larvae ( $\mathrm{n}=18$ fish) (Mann-Whitney Rank Sum Test, $\mathrm{T}=495 ; \mathrm{P}<0.001)$.

Furthermore, to assess the concentration effect, we exposed larvae to $25,50,75$, and $100 \mu \mathrm{M}$ 2-PCPA from 3 to $5 \mathrm{dpf}$ and counted the number of FM1-43FX labeled hair cells in neuromasts. At these doses, zebrafish larvae showed no evidence of morphological abnormalities, suggesting that the larvae do not suffer any drug toxicity or mortality (Fig. $1 \mathrm{H})$. The average numbers ( \pm SEM) of FM1-43FX stained hair cells within each neuromast ranged from $7.2 \pm 0.24$ to $5.05 \pm 0.35$, depending on the concentration of the inhibitor (Fig.1I). We also noticed that the number of hair cells was significantly reduced when exposed to 2-PCPA with concentrations of $75 \mu \mathrm{M}$ or higher. Thus, we chose the $75 \mu \mathrm{M}$ group as a representative in the following discussion. 
To derive a second criterion for determining the reduction of FM1-43FX expression in larvae neuromasts, we further analyzed the brn3c:mGFP transgenic zebrafish which express GFP in hair cells of the lateral line system and inner ear. In $5 \mathrm{dpf}$ larvae, we counted the number of GFP+ cells within neuromasts in control (Fig. 1F) and treated larvae (Fig. 1G). Results showed that the number of GFP+ cells was significantly reduced in neuromasts of 2-PCPA treated larvae ( $7.9 \pm 0.12$ GFP positive cells per neuromast in $75 \mu \mathrm{M}$ 2-PCPA treated larvae, $\mathrm{n}=42$ fish; $10.2 \pm 0.09$ GFP positive cells per neuromast in control larvae, $n=42$ fish; $P<0.001$ ). Our data also revealed that the inhibitor reduced the number of differentiated hair cells in a dose-dependent fashion (Fig. 1J; One way ANOVA; $P<0.05)$, where higher dosage of 2-PCPA caused more severe reduction in cell number. These results suggest that the normal neuromast hair cell development is disturbed by the presence of inhibitor.

Next, we investigated the development of supporting cells as another component of neuromasts. To identify the presence of supporting cells, we used an antibody against Sox2 as a marker, which is expressed in all supporting cells in neuromasts. Fig.2 shows representative images of the Sox2-stained neuromasts from control (Fig. 2A) and $75 \mu \mathrm{M}$ 2-PCPA treated (Fig. 2B) larvae.

Fig. 1. Neuromast hair cell detection in $\mathbf{5} \mathbf{d p f}$ larvae. (A-C) Effect of 2-PCPA on the levels of histone methylation. Confocal projections of neuromasts of $5 \mathrm{dpf}$ control (A) and $75 \mu \mathrm{M}$ 2-PCPA treated larvae (B) that have been labeled by dimethyl H3K4 (2me-H3K4). Larvae were stained (green) by immunocytochemistry for dimethyl H3K4. The level of 2me-H3K4 was increased in the presence of 2-PCPA as compared to the controls. (C) Western blot analysis of protein extracted from control and 2-PCPA treated larvae. 2-PCPA treatment induced accumulation of $2 \mathrm{me}-\mathrm{H} 3 \mathrm{~K} 4$ on global histone. $\beta$-actin levels were included as a control. (D-E) Neuromast hair cells detection with live staining (FM1-43FX) in 5 dpf larvae. Confocal projections of $L 1$ neuromasts of control (D) and 2-PCPA treated larvae (E) at $5 \mathrm{dpf}$ that have been labeled by FM1-43FX for functional hair cells. Fewer FM1-43FX positive cells were developed in $75 \mu \mathrm{M}$ 2-PCPA treated larvae than in control. (F-G) Number of neuromast hair cells assessed with GFP visualisation in transgenic line $\mathrm{Tg}$ (brn3c:mGFP). GFP expression in neuromasts of control (F) and 2-PCPA treated larvae (G) at 5 dpf. There was a significant decrease in the number of hair cells in larvae received 2-PCPA treatment. Nuclei were stained with DAPI. Scale bars $=10 \mu \mathrm{m}$. (H) Both the zebrafish larvae treated with $75 \mu \mathrm{M}$ 2-PCPA from $3 \mathrm{dpf}$ to $5 \mathrm{dpf}$ (lower panel) and control (upper panel) were morphologically normal. (I-J) Quantification of hair cells under 2-PCPA treatment during the early hair cell development period. (I) The average number of functional hair cells perneuromast in 5 dpf zebrafish larvae following 2-PCPA treatment. Graph of functional HCs as seen with FM1-43FX. (J) The average number of differentiated hair cells per neuromast in 5 dpf zebrafish larvae. The number of GFP positive
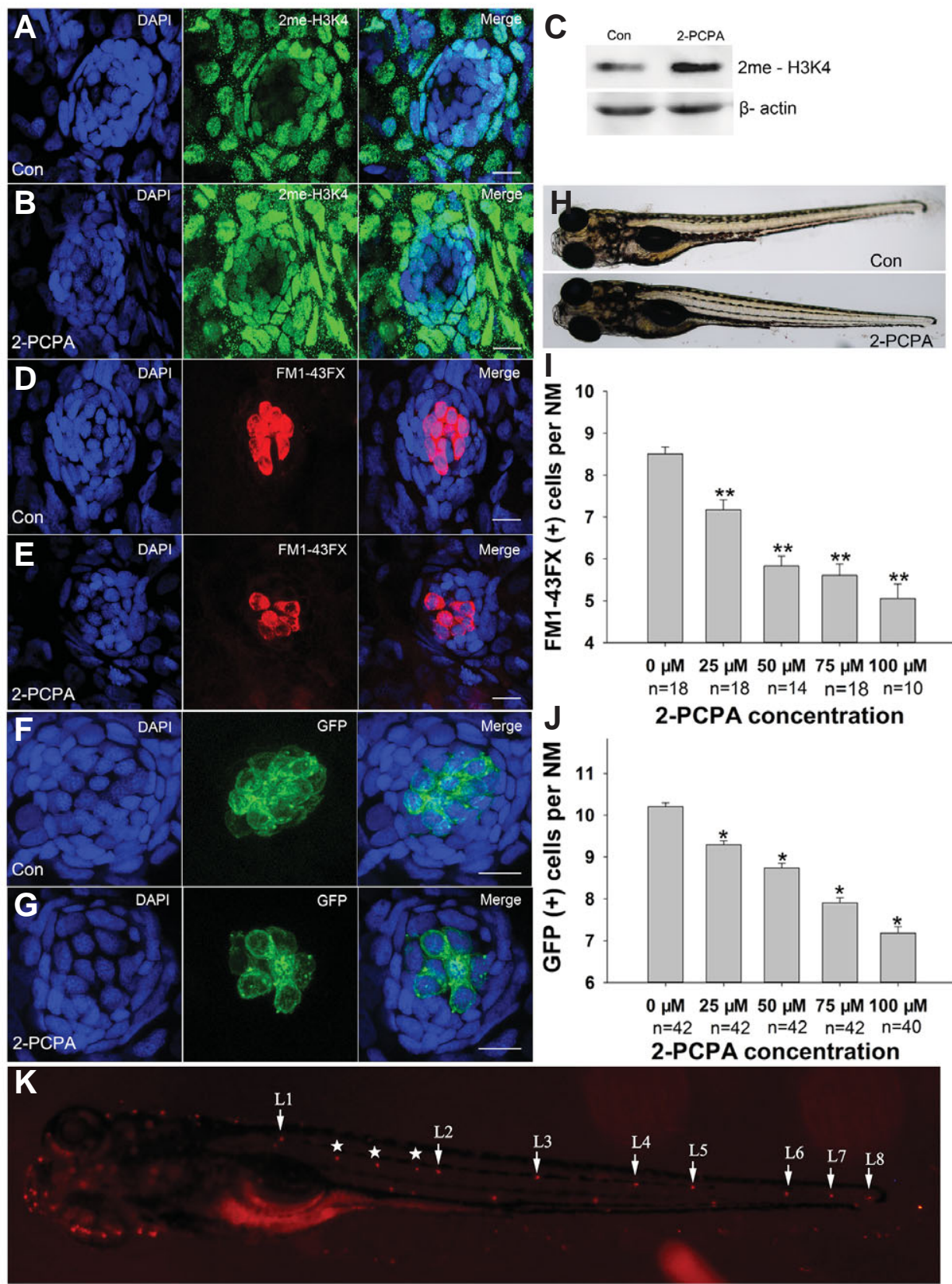

2-PCPA concentration cells were decreased in larvae received 2-PCPA

treatment in a dose-dependent manner. The hair cells of the first four neuromast along the body, L1 to L4, were recorded on one side of each fish (n: total number of fish per 2-PCPA dose). Bars are mean \pm SEM (one-way ANOVA ${ }^{*} P<0.05 ;{ }^{*} P<0.001$ ). (K) Superimposition of a fluorescent image of a 5 dpf zebrafish larva with neuromasts labelled with FM1-43FX. White arrows point to primary NMs L1 to L8 on the left side of the larva, the image shows secondary NMs (*) and a few NMs from the right side of the larva (not labelled). 
Notice that all Sox2-expressing cells are located in the periphery of the neuromast. We counted Sox2-labeled cells in neuromasts in all cases, and found sizable difference between 2-PCPA treated and control larvae (28.1 \pm 0.42 Sox2-expressing cells per neuromast in 75 $\mu \mathrm{M}$ 2-PCPA treated larvae, $\mathrm{n}=18$ fish; $34.6 \pm 0.59$ Sox2-expressing cells per neuromast in control larvae, $n=14$ fish; Student's t-test, $t=9.286$ with 30 degrees of freedom; $P<0.001)$. This result suggests from another perspective that normal LSD1 activity plays an important role in neuromast development.

\section{Exposure to 2-PCPA leads to a decrease in neuromast cell proliferation}

In order to study the cell proliferation in neuromasts in the lateral line of zebrafish in the presence of 2-PCPA, we incubated 3 dpf zebrafish larvae and exposed to 2-PCPA in nucleotide analog Bromodeoxyuridine (BrdU) for 2 days. We analyzed the effect of 2-PCPAon cell proliferation by counting the number of BrdU-labeled cells in the neuromasts. BrdU labeling index was calculated as the ratio of BrdU-labeled nuclei to total DAPI stained nuclei. The results, depicted in Fig. 3, showed that larvae exposed to $75 \mu \mathrm{M}$ 2-PCPA present a significantly reduced number of BrdU stained cells within neuromasts in comparison to control larvae (control BrdU index $=0.265 \pm 0.00766, \mathrm{n}=34$ fish vs. $75 \mu \mathrm{M}$ 2-PCPA BrdU index $=0.199 \pm 0.00572, n=34$ fish; Student's $t$-test, $t=6.859$ with 66 degrees of freedom. $P<0.001)$. Note that the BrdU-labeled cells often distributed in the periphery of the neuromast (Fig. 3A and 3B). We also counted the number of BrdU-labeled cells in the L1-L4 neuromasts of larvae exposed to different concentrations $(0,25$, 50,75 , and $100 \mu \mathrm{M}$ ) of 2-PCPA. In this study, a total of 108 larvae at $5 \mathrm{dpf}$ were studied and at least 12 specimens were recorded for each concentration. From Fig. 3E, we can see clearly that the BrdU index is significantly reduced from the value in controls when treated with 2-PCPA.

Next, we monitored both Myosin VIla and BrdU label in neuromasts of $5 \mathrm{dpf}$ larvae. This experiment allows us to distinguish the

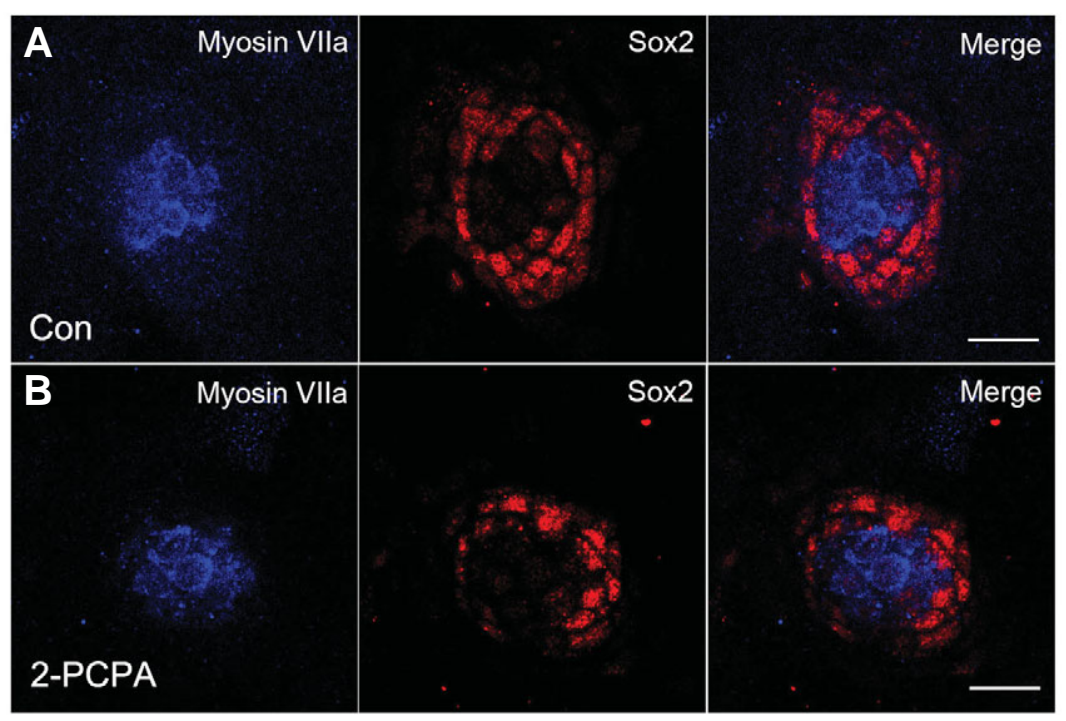

Fig. 2. Supporting cell detection with Sox2 in $\mathbf{5}$ dpf larvae. Confocal projections of neuromasts of control (A) and $75 \mu \mathrm{M}$ 2-PCPA treated larvae (B) at $5 \mathrm{dpf}$ that have been labeled by Sox2 for supporting cells. Fewer Sox2 positive cells were developed in 2-PCPA treated embryos than in the controls. Hair cells were stained with Myosin VIla (blue). Red spots represented Sox2 signal. Scale bars, $10 \mu \mathrm{m}$. newly formed hair cells from cell proliferation (Fig. 3 C,D). In 75 $\mu \mathrm{M}$ 2-PCPA treated neuromasts, BrdU incorporation was mainly detected in the periphery of the neuromast and there was very little overlap of signals. In control fish, however, a considerable amount of Myosin VIla-expressing cells colabeled with BrdU (Fig. 3F; control 3.5 \pm 0.18 Myosin $\mathrm{VIla}^{+} \mathrm{BrdU}^{+}$cells per neuromast, $\mathrm{n}=14$ fish vs. $75 \mu \mathrm{M}$ 2-PCPA $1.67 \pm 0.19$ Myosin VIla+ $\mathrm{BrdU}^{+}$cells per neuromast, $n=17$ fish; Student's t-test, $t=6.978$ with 29 degrees of freedom; $\mathrm{P}<0.001)$. To evaluate the extent of overlap between Sox2 protein expression and proliferative cells in neuromasts, we labeled cells with anti-Sox2 and anti-BrdU antibodies. We confirmed that the majority of BrdU positive cells also expressed Sox2 under all conditions (control and 2-PCPA treated). Fig. 3 C,D show representative images of the stained neuromasts from control and 2-PCPA treated fish, respectively. Aquantitative analysis of the results for each case is presented in Fig. 3G. The average numbers ( \pm SEM) of BrdU-positive cells that also expressed Sox2 protein in control and $75 \mu \mathrm{M} 2-\mathrm{PCPA}$ treated fish were 10.1 \pm 0.3 ( $n=14$ fish) and $7.7 \pm 0.23$ ( $n=17$ fish), respectively (Student's t-test, $t=6.579$ with 29 degrees of freedom; $P<0.001$ ). These results indicate that LSD1 demethylase activity serves as a regulator of neuromast cell proliferation and LSD1 inhibition can significantly reduce the fraction of BrdU stained cells in neuromasts.

Cell proliferation requires coordinated interaction of cyclins and cyclin-dependent kinases to drive cells through the cell cycle. To determine the mechanisms of LSD's inhibition of cell cycle progression, we performed real-time RT-PCR analysis for the cell cycle regulators p21 and p27. As shown in Fig. $3 \mathrm{H}, \mathrm{l}$, we observed an overall increase in the mRNA levels of the expressions of p21 and p27 in larvae treated with 2-PCPA in comparison to those in control fish. The increase for p21 in 2-PCPA treated larvae could reach as high as $50 \%$ and the increase of $\mathrm{p} 27$ was less significant. Our results hence show that LSD1 inhibition in zebrafish induce an increase in both p21 and p27 expressions.

\section{Exposure to high concentration of 2-PCPA induces cellular apoptosis}

To determine whether 2-PCPA treatment induces cell damage, we exposed $3 \mathrm{dpf}$ zebrafish larvae to 2-PCPAconcentrations ranging from 25 to $150 \mu \mathrm{M}$ for 2 days and stained neuromast cells with the vital dye acridine orange $(\mathrm{AO})$ at $5 \mathrm{dpf}$. For cases with lower concentrations $(\leq 100 \mu \mathrm{M})$, we found that neuromasts in all specimens contained the same number of $\mathrm{AO}$ positive cells as controls. In control larvae, 5 out of 56 neuromasts showed AO-positive cells with an average of 0.78 positive cell per neuromast examined. In 75 $\mu \mathrm{M}$ 2-PCPA treatment larvae, 9 out of 88 neuromasts exhibited AO-positive cells and, on average, 0.64 AO-positive cells were seen per neuromast. However, for the case of highest concentration $(150 \mu \mathrm{M})$, the AO-positive cells were seen in 12 out of 64 examined neuromasts with an average of 1.2 positive cells per neuromast (Fig. 4 A,B,E). We also detected an increased of cleaved caspase-3 immunohistochemistry within $150 \mu \mathrm{M}$ 2-PCPA treated group (Fig. 4C). These observations indicate that lower concentrations of 2-PCPA, ranging from 25 to $100 \mu \mathrm{M}$, induce no observable toxic effects on neuromast cells, while a 


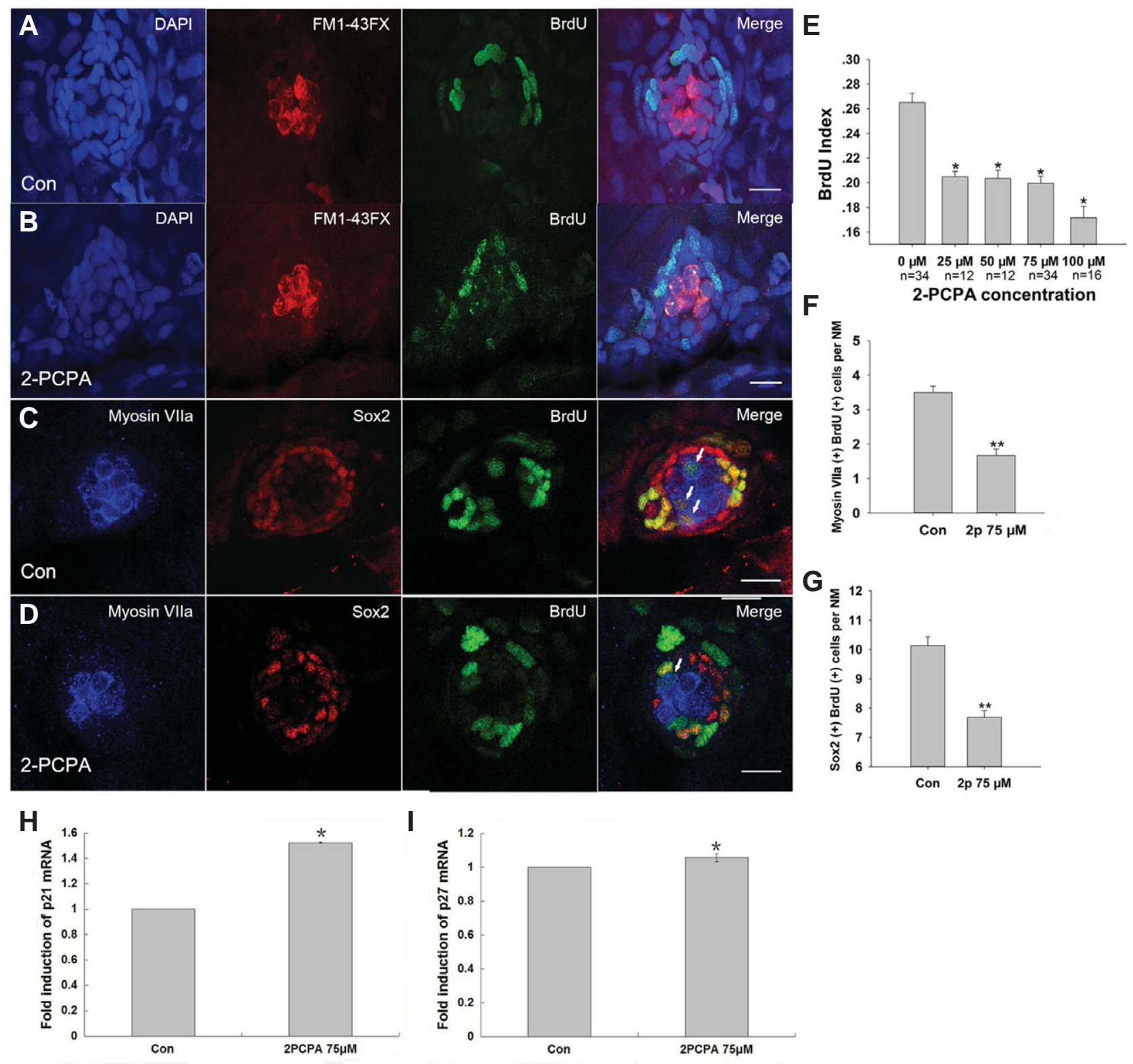

Fig. 3. 2-PCPA treatment inhibits neuromast cell proliferation. (A-B) Effect of 2-PCPA on neuromast cell proliferation. Confocal projections of neuromasts of $5 \mathrm{dpf}$ control (A) and $75 \mu \mathrm{M}$ 2-PCPA treated larvae (B) that have been labeled by BrdU for proliferating cells. The number of BrdU-labeled cells was much larger in control than in 2-PCPA treated larvae, and BrdU-labeled cells often located in the periphery of the neuromast. Green spots represented BrdU signal. HCs were labeled with FM1-43FX (red) and nuclei were stained with DAPI (b/ue). (C-D) 2-PCPA treatment decreased the numbers of both newly formed HCS and SCs within neuromasts. Confocal projections of neuromasts of control (C) and 2-PCPA treated larvae (D) at 5 dpf. HCs were labeled with Myosin VIla (blue) and SCs were stained with Sox2 (red). Green spots represented BrdU signal. White arrows indicated hair cells that were derived from cell proliferation. Scale bar $=10 \mu \mathrm{m}$. (E) Quantification of replicating cells in neuromasts in the experimental conditions. BrdU index was higher in the control relative to the 2-PCPA treated larvae (n: total number of fish per 2-PCPA dose). (F) Mean Myosin VIla-expressing cells colabeled with BrdU per neuromast (NM) in control and 2-PCPA treatment larvae. (G) Quantification of replicating cells colabeled with Sox2 per neuromast (NM) under each condition. The labeled cells of the first four neuromasts along the body, $L 1$ to $L 4$, were recorded on one side of each fish. Bars are mean \pm SEM (one-way ANOVA $\left.{ }^{*} P<0.05,{ }^{*} P<0.001\right)$. $(\mathbf{H}, \mathbf{I})$ Real-time RT-PCR analysis showed that 2-PCPA treatment increased the expressions of $p 21$ and p27 at mRNA levels. The bars represent the mean \pm SEM of ratio of $p 21$ and p27/GAPDH in the real-time RT-PCR data.

higher dosage of $150 \mu \mathrm{M}$ can affect cell survival.

We next focused on the transgenic line brn3c:mGFP, which allowed us to identify dying hair cells in zebrafish neuromasts. For specimens either in control or 2-PCPA treated groups with lower dosage $(\leq 100 \mu \mathrm{M})$, we occasionally detected dying hair cells in neuromasts. On the contrary, the emergence of dying hair cells became quite frequent in larvae exposed to $150 \mu \mathrm{M}$ 2-PCPA. Representative images of neuromasts are presented in Fig. 4D. Notice that in $150 \mu \mathrm{M}$ 2-PCPA treated larvae, dying GFP-labeled hair cells were extruded from the center of the neuromasts as they 

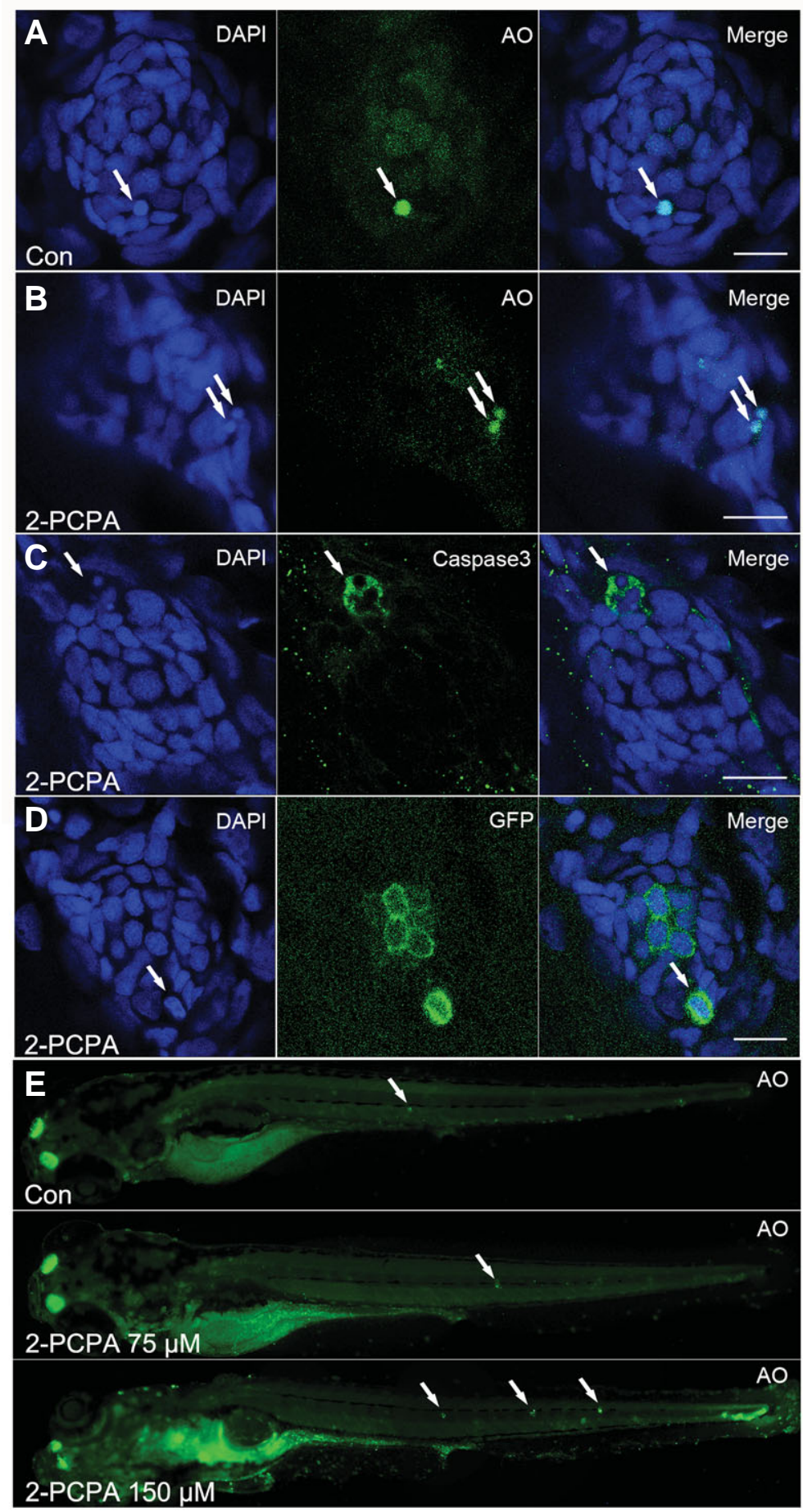

Fig. 4. High concentration of 2-PCPA treatment leads to apoptosis. (A-E) 2-PCPA treatment at high concentration $(150 \mu \mathrm{M})$ induced an enhancement of cellular apoptosis within neuromasts. A-B: AO staining in the neuromast of a control (A) and a 2-PCPA treated larva (B) at $5 \mathrm{dpf}$. White arrows indicated AOpositive cells. (C) Cleaved Caspase-3 staining in the neuromast of a $150 \mu \mathrm{M}$ 2-PCPA treated larva at $5 \mathrm{dpf}$ (D) The detection of hair cell death in neuromast. Neuromast images from brn3c:mGFP larvae treated with $150 \mu \mathrm{M} 2-P C P A$. White arrows in (D) showed dying hair cells being extruded from the neuromast. Scale bar $=10 \mu \mathrm{m}$. (E) $150 \mu \mathrm{M}$ 2-PCPA treated larva (lower panel) have high levels of acridine orange $(A O)$ staining (white arrows) in neuromasts, compared with control (upper panel) and $75 \mu \mathrm{M}$ 2-PCPA treated larva (middle panel) at $5 \mathrm{dpf}$. became round-shaped (arrow). Our results show that cell death is normally quite rare in developing neuromasts, but is rather common in larvae treated with high concentration of 2-PCPA. This result confirms that LSD1 can influence the survival of mechanosensory hair cell.

\section{Discussion}

Histone methyltransferases have roles in various biological processes during development, and many studies have shown that misregulartion of histone methyltransferases is linked with human diseases such as cancer and neurological disorders (Albert and Helin, 2010; Black et al., 2012; Cloos et al., 2008; Pedersen and Helin, 2010). As the first discovered histone demethylase, lysine-specific demethylase 1 (LSD1) functions as a transcriptional coregulator. Genetic ablation of LSD1 induces early embryonic lethality in mice, suggesting a requirement for LSD1 activity in normal embryonic development (Wang et al., 2009; Wang et al., 2007). It is generally accepted that LSD1 plays a role in REST-dependent transcriptional repression of neuronal-specific genes, and serves as a regulator of neuronal development (Hakimi et al., 2002). It has been reported that LSD1 is highly expressed in developing CNS and is necessary for zebrafish neural system development. In an early study, Sun et al. reported that a dramatic reduction of neural stem cell proliferation could be induced by knockdown of LSD1 expression or inhibition of LSD1 activity in adult mouse brains (Sun et al., 2010). Besides, Jie et al., showed that LSD1 MO or inhibition of LSD1 activity with 2-PCPA treatment could induce nerve cell apoptosis during zebrafish embryonic brain development (Jie et al., 2009).

In this study, we have used the lateral line of zebrafish as a model system to assess the role of LSD1 in neuromast development. It has been previously noted that the lateral line neuromasts enter a phase of maturation with functional hair cells around 3 days post-fertilization (dpf) (Ma and Raible, 2009; Raible and Kruse, 2000). Hence, the period between 3-5 dpf is a good time window to study hair cell differentiation. We observed a significant reduction in the number of functional hair cells when 2-PCPA was applied to larvae starting from 3 $\mathrm{dpf}$ and lasted for 2 days. We also found that 2-PCPA treatment decreased the number of Sox2 positive supporting cells. Taken together, these data indicate that LSD1 is involved in lateral line neuromast development in zebrafish larvae and inhibition of LSD1 activity could lead to a reduction in the number of both hair cells and supporting cells. The differences in the number of these two types of cells between 2-PCPA treated and untreated larvae can be understood as results of decrement of cell proliferation and/or increment of cell death. We first evaluated cell proliferation in neuromasts after 2-PCPA treatment. It is well known that hair cells could be renewed continuously probably throughout the whole life of zebrafish larvae neuromast. The renewed HCs are mainly generated from continuous proliferation of SCs (Hernandez et al., 2007). Our data showed that compared to the controls, the number of BrdU-positive cells was strikingly reduced in the presence of 2-PCPA with concentrations of $25 \mu \mathrm{M}$ or higher. BrdU labeling index did not show significant differences among the $25 \mu \mathrm{M}$, $50 \mu \mathrm{M}$ and $75 \mu \mathrm{M}$ groups, but again markedly reduced in 100 
MM 2-PCPA-treated group. These results suggested that 2-PCPA suppression effect might meet a platform from dosages of 25 to $75 \mu \mathrm{M}$, and become more severe with increasing concentration over $100 \mu \mathrm{M}$.

Cell proliferation requires coordinated interaction of cyclins and cyclin-dependent kinases (Cdks) to drive cell cycle transitions. Cyclin-dependent kinases inhibitors (CKIs), in particular those of the Cip/Kip family (p21, p27, and p57), can inhibit a broad range of cyclin/Cdk complexes and cause cell-cycle arrest. We then investigated the expression levels of p21 and p27 in zebrafish and found that 2-PCPA treatment increased the expression of p21 and p27 at mRNA levels. In particular, high p21 expression was observed in treatment group. These results suggest that the inhibition of neuromast cell proliferation with 2-PCPA might be induced by the up-regulation of p21 and p27, in particular p21. Previous work has shown that $\mathrm{p} 21$ and p27 are involved in the regulation of pRb activity and play roles in the development of cochlear hair cells as a cell-selective regulator of cell proliferation (Liu and Zuo, 2008; Lowenheim et al., 1999; Mantela et al., 2005). CKIs negatively regulate the activity of CDKs, which maintain the phosphorylation of $\mathrm{Rb}$ protein in a hypophosphorylated form and bind to a family of transcription factors called E2Fs, resulting in transcriptional repression and cell cycle arrest. Recently, it has been reported that $\mathrm{pRb}$ acts as a regulator of cell proliferation and participates in the maintenance of the postmitotic state and the survival of hair cells (Weber et al., 2008). Future studies should be directed toward understanding whether the $\mathrm{pRb}$ pathway is involved in the development of hair cells by LSD1 inhibition and the exact function of LSD1 in this pathway.

Reduced number of hair cells and supporting cells may also be induced by increased cell death. To analyze such a possibility, we further investigated the effect of 2-PCPA treatment on cell death in developing neuromasts. Our results showed that cell death was quite rare in normal developing neuromast and those treated with low concentration $(\leq 100 \mu \mathrm{M})$ of 2 -PCPA, but became common in larvae treated with high concentration of 2-PCPA. Low level of hair cell death in control neuromasts indicated that hair cells in the neuromasts were undergoing constant turnover (Williams and Holder, 2000). Therefore, abnormal hair cell and supporting cell development after 2-PCPA treatment might be mainly caused by the reduction in cell proliferation.

In conclusion, our data indicated that the LSD1 demethylase activity was effectively blocked after 2 days exposure of 2-PCPA to zebrafish neuromasts, resulting in a reduction in the number of both hair cells and supporting cells. With BrdU incorporation analysis, we showed that LSD1-mediated demethylation was indispensable for cell proliferation in the neuromasts. This study could be useful for better understanding of the connection between epigenetic regulatory abnormalities and hair cell and supporting cell development.

\section{Materials and Methods}

\section{Zebrafish strains and maintenance}

Fish and embryos were maintained in our facility according to standard procedures. The transgenic line brn3c:mGFP was obtained from the laboratory of Pro. Zhengyi Chen, while all other embryos were obtained from natural spawning of wild type adults. The $\mathrm{Tg}$ (brn3c:mGFP) ${ }^{\text {s356t }}$ transgenic zebrafish express GFP in hair cells under the control of the brn3c (pou4f3) promoter and are targeted to the plasma membrane with a GAP-43 membrane targeting sequence (Xiao et al., 2005). Zebrafish were staged according to Kimmel et al., (Kimmel et al., 1995) and raised at $28.5^{\circ} \mathrm{C}$ in Petri dishes. The age of embryos or larvae are described as days post-fertilization (dpf).

\section{Pharmacological treatments}

LSD1 inhibitor, 2-PCPA (trans-2-phenylcyclopropylamine; SigmaAldrich), were dissolved in $\mathrm{ddH}_{2} \mathrm{O}$ at stock concentrations of $200 \mathrm{mM}$, and then diluted to the concentrations indicated in fish water. Dose-response data were obtained by treating $3 \mathrm{dpf}$ larvae for 2 days with 2-PCPA containing fish water, and then larvae were fixed. In all experimental conditions, control groups were maintained in parallel under same conditions, but without 2-PCPA treatment.

\section{FM1-43FX labeling of neuromast hair cells}

Neuromast hair cells were labeled by exposing the live $5 \mathrm{dpf}$ larvae in $3 \mu \mathrm{M}$ FM1-43FX (Invitrogen; F-35355) for $45 \mathrm{~s}$ under darkened conditions. After quickly rinsed 3 times with fresh fish water, the labeled larvae were then anesthetized with MS-222 (3-aminobenzoic acid ethyl ester, methanesolfonate salt, Sigma-Aldrich) and fixed in $4 \%$ paraformaldehyde (PFA) for next analysis. The labeled hair cells of the first four neuromast along the body, L1 to L4, were recorded on one side of each fish using fluorescence microscopy with a 40xobjective.

\section{BrdU treatment and analysis}

Zebrafish larvae were treated with $10 \mathrm{mM} 5$-bromo-2-deoxyuridine (BrdU; Sigma) for 2 days at $28.5^{\circ} \mathrm{C}$. Larvae were fixed with $4 \%$ PFA overnight at $4^{\circ} \mathrm{C}$. BrdU incorporation was detected by fluorescent immunostaining. Fixed samples were washed 3 times in PBS containing $0.5 \%$ Triton X-100 (PBT-2) and incubated in $2 \mathrm{~N} \mathrm{HCl}$ (in PBT-2) for $0.5 \mathrm{~h}$ at $37^{\circ} \mathrm{C}$. After 3 rinses in PBT-2, samples were blocked in $10 \%$ normal goat serum for $1 \mathrm{~h}$ at RT before primary incubation. Mouse anti-BrdU (Santa Cruz Biotechnology Inc. cat. no. sc-32323) primary antibody was used at 1:200 dilution in PBT-2.

\section{Immunofluorescence analysis}

For immunohistochemistry analysis, $5 \mathrm{dpf}$ zebrafish larvae were fixed in $4 \%$ PFA and were permeabilized with $0.5 \%$ Triton X-100 in PBS for 30 minutes, followed by incubation in blocking solution for 1 hour. The following antibodies were used as primary antibodies: rabbit anti-dimethyl H3K4 (1:200; Cell Signaling Technology); rabbit anti-Cleaved Caspase-3 (1:200; Cell Signaling Technology); goat anti-Sox2 (1:100; Santa Cruz Biotechnology); rabbit anti-Myosin VIla (1:200). Nuclear was labeled with DAPI (1:800; Sigma) for 20 mins at room temperature.

\section{Western blotting}

Total protein was isolated from $5 \mathrm{dpf}$ zebrafish larvae using AllPrep DNA/RNA/Protein Mini Kit (QIAGEN, Hilden, Germany) according to the manufacturer's instructions. Embryo proteins were separated in SDS-PAGE, and transferred onto PVDF membrane (Immobilon-P; Millipore, Bedford, MA, USA). The proteins were incubated with rabbit polyclonal anti-dimethyl H3K4 (1:1000; Cell Signaling Technology).

\section{RNA isolaton and quantitative real-time RT-PCR}

The total RNA from zebrafish was purified using Trizol reagent (Invitrogen) according to manufacturer's instructions. Reverse transcription was performed with Superscript III (Invitrogen) following manufacturer's instructions. The cDNA was analyzed by real-time PCR using SYBR Green Master Mix and the following primer pairs: p21 forward 5'-CCTACGTTCACTCGGTAATGG-3', reverse 5'-TGGAAGTCTCCGCCCTCT-3'; p27 forward 5'-CGGGAATCACGACTGTAGG-3', reverse 5'-TGTGGGTGTCGGACTCAAT-3'; GAPDH forward 5'-TGTAAGCAATGCCTCCTG-3'; reverse 5'-CATCAACGGTCTTCTGTG -3'. The amount of mRNA was calculated using GAPDH as the endogenous control.

\section{Acridine orange staining}

Apoptosis in whole zebrafish larvae were stained with the vital dye ac- 
ridine orange (acridinium chloride hemi-[zinc chloride], AO; Sigma-Aldrich) (Abrams et al., 1993). Larvae were placed in $2 \mu \mathrm{g} / \mathrm{ml}$ AO in fish water in the dark at $28^{\circ} \mathrm{C}$ for 30 minutes. Larvae were then washed with fish water 3 times for 10 minutes each. Images were obtained with confocal microscopy (TCS SP5, Leica) and were processed using Photoshop software (Adobe).

\section{Statistical analysis}

All statistical analysis was performed using SPSS (version 13.0 for Windows) and SigmaPlot (version 12.0 for Windows) in this study. Prior to analysis, all data were first examined for normality and homogeneity of variances by the Shapiro-Wilk test and Levene's test, respectively. Data were analyzed using either t-tests or analysis of variance (ANOVA) with multiple comparisons. Data are described as mean $\pm \mathrm{SEM}$; $\mathrm{P}<0.05$ was considered statistically significant and $\mathrm{P}<0.001$ was considered highly significant.

\section{Acknowledgments}

The authors would like to thank Min Yu, Jingying $\mathrm{Hu}$, and Shaoyang Sun for their expert fish care, and Yalin Huang for technical assistance. This work was supported by grants from the Major State Basic Research Development Program of China (973 Program) (2011CB504506), the National Natural Science Foundation of China (No. 81230019, 81070793, 30901668), the National Natural Science Foundation for Youth of China (No.81100721), and Sponsored by Shanghai Rising-Star Program (12QA1400500), the Program for Changjiang Scholars and Innovative Research Team in University(IRT1010), the Innovation Programme of Major Basic Research Project, the Science and Technology Commission of Shanghai Municipality (09DJ1400602), the Program of Outstanding Shanghai Academic Leader (11XD1401300) and the Program of Leading Medical Personnel in Shanghai.

\section{References}

ABRAMS J M, WHITE K, FESSLER L I and STELLER H (1993). Programmed cell death during Drosophila embryogenesis. Development 117: 29-43.

ALBERT M and HELIN K (2010). Histone methyltransferases in cancer. Semin Cell Dev Biol 21: 209-220.

AMAN A, NGUYEN M and PIOTROWSKI T (2011). Wnt/beta-catenin dependent cell proliferation underlies segmented lateral line morphogenesis. Dev Biol 349: 470-482.

AMAN A and PIOTROWSKI T (2008). Wnt/beta-catenin and Fgf signaling control collective cell migration by restricting chemokine receptor expression. Dev Cell 15: 749-761.

BERGER S L (2002). Histone modifications in transcriptional regulation. Curr Opin Genet Dev 12: 142-148.

BLACK J C, VAN RECHEM C and WHETSTINE J R (2012). Histone lysine methylation dynamics: establishment, regulation, and biological impact. Mol Cell 48: 491-507.

CHITNIS A B, NOGARE D D and MATSUDA M (2012). Building the posterior lateral line system in zebrafish. Dev Neurobiol 72: 234-255.

CHIULL, CUNNINGHAM LL, RAIBLE DW, RUBELE W and OU HC (2008). Using the zebrafish lateral line to screen for ototoxicity. JAssoc Res Otolaryngol 9: 178-190.

CLOOS P A, CHRISTENSEN J, AGGER K and HELIN K (2008). Erasing the methyl mark: histone demethylases at the center of cellular differentiation and disease. Genes Dev 22: 1115-1140.

DAMBLY-CHAUDIERE C, CUBEDO N and GHYSENA(2007). Control of cell migration in the development of the posterior lateral line: antagonistic interactions between the chemokine receptors CXCR4 and CXCR7/RDC1. BMC Dev Biol 7: 23.

DAMBLY-CHAUDIERE C, SAPEDE D, SOUBIRAN F, DECORDE K, GOMPEL N and GHYSEN A (2003). The lateral line of zebrafish: a model system for the analysis of morphogenesis and neural development in vertebrates. Biol Cell 95: 579-587.

FRITZSCH B, PAULEY S and BEISEL KW (2006). Cells, molecules and morphogenesis: the making of the vertebrate ear. Brain Res 1091: 151-171.

GALE J E, MARCOTTI W, KENNEDY H J, KROS C J and RICHARDSON G P (2001). FM1-43 dye behaves as a permeant blocker of the hair-cell mechanotransducer channel. J Neurosci 21: 7013-7025.
GHYSEN A and DAMBLY-CHAUDIERE C (2007). The lateral line microcosmos Genes Dev 21: 2118-2130.

HADDON C and LEWIS J (1996). Early ear development in the embryo of the zebrafish, Danio rerio. J Comp Neurol 365: 113-128.

HAKIMI MA, BOCHARDA, CHENOWETH J, LANE WS, MANDEL G and SHIEKHATTAR R (2002). A core-BRAF35 complex containing histone deacetylase mediates repression of neuronal-specific genes. Proc Natl Acad Sci USA 99: 7420-7425.

HARRIS J A, CHENG A G, CUNNINGHAM L L, MACDONALD G, RAIBLE D W and RUBEL E W (2003). Neomycin-induced hair cell death and rapid regeneration in the lateral line of zebrafish (Danio rerio). J Assoc Res Otolaryngol 4: 219-234.

HERNANDEZ P P, OLIVARI F A, SARRAZIN A F, SANDOVAL P C and ALLENDE $M L$ (2007). Regeneration in zebrafish lateral line neuromasts: Expression of the neural progenitor cell marker Sox2 and proliferation-dependent and-independent mechanisms of hair cell renewal. Dev. Neurobiol. 67: 637-654.

HILL A J, TERAOKA H, HEIDEMAN W and PETERSON R E (2005). Zebrafish as a model vertebrate for investigating chemical toxicity. Toxicol Sci 86: 6-19.

HU X, LI X, VALVERDE K, FU X, NOGUCHI C, QIU Y and HUANG S (2009). LSD1mediated epigenetic modification is required for TAL1 function and hematopoiesis. Proc Natl Acad Sci USA 106: 10141-10146.

JENUWEIN T and ALLIS C D (2001). Translating the histone code. Science 293: 1074-1080.

JIE Z, LI T, JIA-YUN H, QIU J, PING-YAO Z and HOUYAN S (2009). Trans-2-phenylcyclopropylamine induces nerve cells apoptosis in zebrafish mediated by depression of LSD1 activity. Brain Res Bull 80: 79-84.

KELLEY M W (2006). Hair cell development: Commitment through differentiation. Brain Research 1091: 172-185.

KIMMELC B, BALLARD WW, KIMMELS R, ULLMANN B and SCHILLING TF (1995) Stages of Embryonic-Development of the Zebrafish. Dev Dynam 203: 253-310.

KOOISTRA S M and HELIN K (2012). Molecular mechanisms and potential functions of histone demethylases. Nat Rev Mol Cell Biol 13: 297-311.

KOUZARIDEST (2007). Chromatin modifications and their function. Cell128:693-705

LECAUDEY V, CAKAN-AKDOGAN G, NORTON W H and GILMOUR D (2008). Dynamic Fgf signaling couples morphogenesis and migration in the zebrafish lateral line primordium. Development 135: 2695-2705.

LIU Z and ZUO J (2008). Cell cycle regulation in hair cell development and regeneration in the mouse cochlea. Cell Cycle 7: 2129-2133.

LOHSE B, KRISTENSEN J L, KRISTENSEN L H, AGGER K, HELIN K, GAJHEDE $\mathrm{M}$ and CLAUSEN R P (2011). Inhibitors of histone demethylases. Bioorg Med Chem 19: 3625-3636.

LOWENHEIM H, FURNESS D N, KIL J, ZINN C, GULTIG K, FERO M L, FROST D, GUMMER A W, ROBERTS J M, RUBEL E W, HACKNEY C M and ZENNER $H$ $P$ (1999). Gene disruption of p27(Kip1) allows cell proliferation in the postnatal and adult organ of corti. Proc Natl Acad Sci USA 96: 4084-4088.

MAE Y and RAIBLE D W (2009). Signaling pathways regulating zebrafish lateral line development. Curr Biol 19: R381-386.

MANTELA J, JIANG Z, YLIKOSKI J, FRITZSCH B, ZACKSENHAUS E and PIRVOLA $U$ (2005). The retinoblastoma gene pathway regulates the postmitotic state of hair cells of the mouse inner ear. Development 132: 2377-2388.

MARTIN C and ZHANG Y (2005). The diverse functions of histone lysine methylation Nat Rev Mol Cell Biol 6: 838-849.

METZGER E, WISSMANN M, YIN N, MULLER J M, SCHNEIDER R, PETERS A H, GUNTHER T, BUETTNER R and SCHULE R (2005). LSD1 demethylates repressive histone marks to promote androgen-receptor-dependent transcription. Nature 437: 436-439.

MEYERS JR, MACDONALD RB, DUGGANA, LENZID, STANDAERT D G, CORWIN J T and COREY D P (2003). Lighting up the senses: FM1-43 loading of sensory cells through nonselective ion channels. J Neurosci 23: 4054-4065.

MONTGOMERY J, CARTON G, VOIGTR, BAKER C and DIEBEL C (2000). Sensory processing of water currents by fishes. Philos Trans R Soc Lond B Biol Sci 355 1325-1327.

NECHIPORUK A and RAIBLE D W (2008). FGF-dependent mechanosensory organ patterning in zebrafish. Science 320: 1774-1777.

NICOLSON T (2005). The genetics of hearing and balance in zebrafish. Annu Rev Genet 39: 9-22. 
OU H C, RAIBLE D W and RUBEL E W (2007). Cisplatin-induced hair cell loss in zebrafish (Danio rerio) lateral line. Hear Res 233: 46-53.

OWENS K N, SANTOS F, ROBERTS B, LINBO T, COFFINAB, KNISELY AJ, SIMON J A, RUBEL E W and RAIBLE D W (2008). Identification of genetic and chemical modulators of zebrafish mechanosensory hair cell death. PLoS Genet4: 1000020.

PEDERSEN M T and HELIN K (2010). Histone demethylases in development and disease. Trends Cell Biol 20: 662-671.

PROVENZANO M J and DOMANN F E (2007). A role for epigenetics in hearing: Establishment and maintenance of auditory specific gene expression patterns. Hear Res 233: 1-13.

RAIBLE D W and KRUSE G J (2000). Organization of the lateral line system in embryonic zebrafish. J Comp Neurol 421: 189-198.

RICE J C and ALLIS C D (2001). Histone methylation versus histone acetylation: new insights into epigenetic regulation. Curr Opin Cell Biol 13: 263-273.

ROTH S Y, DENU J M and ALLIS C D (2001). Histone acetyltransferases. Annu Rev Biochem 70: 81-120.

SCHMIDT D M and MCCAFFERTY D G (2007). trans-2-Phenylcyclopropylamine is a mechanism-based inactivator of the histone demethylase LSD1. Biochemistry 46: 4408-4416.

SCOUMANNEA and CHEN X B (2007). The lysine-specific demethylase 1 is required for cell proliferation in both p53-dependent and -independent manners. J. Biol. Chem. 282: 15471-15475.

SHI Y, LAN F, MATSON C, MULLIGAN P, WHETSTINE J R, COLE P A and CASERO $\mathrm{RA}(2004)$. Histone demethylation mediated by the nuclear amine oxidase homolog LSD1. Cell 119: 941-953.

SUN G, ALZAYADY K, STEWART R, YE P, YANG S, LI W and SHI Y (2010). Histone demethylase LSD1 regulates neural stem cell proliferation. $\mathrm{Mol} \mathrm{Cell} \mathrm{Biol}$ 30: 1997-2005.
TON C and PARNG C (2005). The use of zebrafish for assessing ototoxic and otoprotective agents. Hear Res 208: 79-88.

VAN TRUMP W J, COOMBS S, DUNCAN K and MCHENRY M J (2010). Gentamicin is ototoxic to all hair cells in the fish lateral line system. Hear Res 261: 42-50.

WANG J, HEVI S, KURASH J K, LEI H, GAY F, BAJKO J, SU H, SUN W, CHANG H, XU G, GAUDET F, LIE and CHENT (2009). The lysine demethylase LSD1 (KDM1) is required for maintenance of global DNA methylation. Nat Genet 41: 125-129.

WANG J, SCULLY K, ZHU X, CAI L, ZHANG J, PREFONTAINE G G, KRONES A OHGI K A, ZHU P, GARCIA-BASSETS I, LIU F, TAYLOR H, LOZACH J, JAYES F L, KORACH K S, GLASS C K, FU X D and ROSENFELD M G (2007). Opposing LSD1 complexes function in developmental gene activation and repression programmes. Nature 446: 882-887.

WEBER T, CORBETT M K, CHOW L M, VALENTINE M B, BAKER S J and ZUO $J$ (2008). Rapid cell-cycle reentry and cell death after acute inactivation of the retinoblastoma gene product in postnatal cochlear hair cells. Proc Natl Acad Sci USA 105: 781-785.

WILLIAMS J A and HOLDER N (2000). Cell turnover in neuromasts of zebrafish larvae. Hear Res 143: 171-181.

XIAO T, ROESER T, STAUB W and BAIER H (2005). A GFP-based genetic screen reveals mutations that disrupt the architecture of the zebrafish retinotectal projection. Development 132: 2955-2967.

YANG M, CULHANE J C, SZEWCZUK L M, JALILI P, BALL H L, MACHIUS M, COLE $P A$ and $Y U H$ (2007). Structural basis for the inhibition of the LSD1 histone demethylase by the antidepressant trans-2-phenylcyclopropylamine. Biochemistry 46: 8058-8065.

ZHANG Y and REINBERG D (2001). Transcription regulation by histone methylation: interplay between different covalent modifications of the core histone tails. Genes Dev 15: 2343-2360. 


\section{Further Related Reading, published previously in the Int. J. Dev. Biol.}

Patterning the nervous system through development and evolution

Alain Ghysen, Christine Dambly-Chaudière and David W. Raible

Int. J. Dev. Biol. (2010) 54: S1-S14

Development of the posterior lateral line system in Thunnus thynnus, the atlantic bluefin tuna, and in its close relative Sarda sarda

Alain Ghysen, Kevin Schuster, Denis Coves, Fernando de la Gandara, Nikos Papandroulakis and Aurelio Ortega

Int. J. Dev. Biol. (2010) 54: 1317-1322

Hair cell regeneration in the avian auditory epithelium Jennifer S. Stone and Douglas A. Cotanche

Int. J. Dev. Biol. (2007) 51: 633-647

Cellular commitment and differentiation in the organ of Corti

Matthew W. Kelley

Int. J. Dev. Biol. (2007) 51: 571-583

Pocket proteins and cell cycle regulation in inner ear development Sonia M.S. Rocha-Sanchez and Kirk W. Beisel

Int. J. Dev. Biol. (2007) 51: 585-595

5 yr ISI Impact Factor $(2011)=2.959$

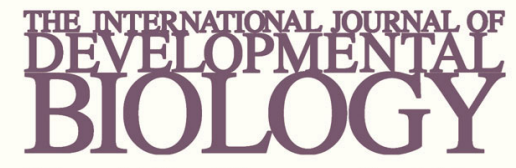

Volume 54 Nos. 6/7
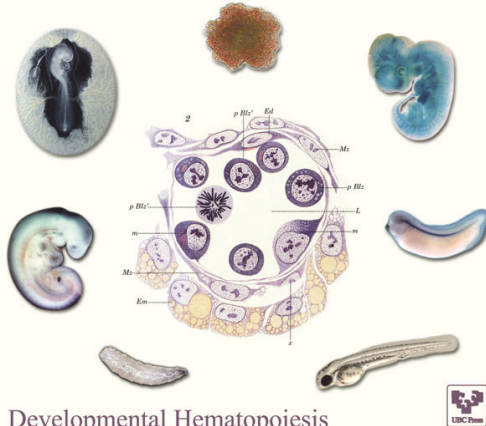

Developmental Hematopoiesis

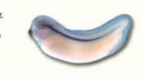

क्w

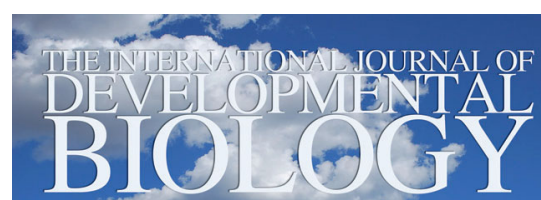

Volume 56 Nos. 10/11/12 Special Issue
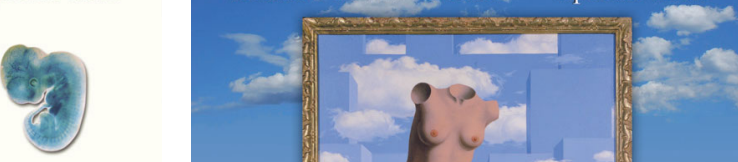

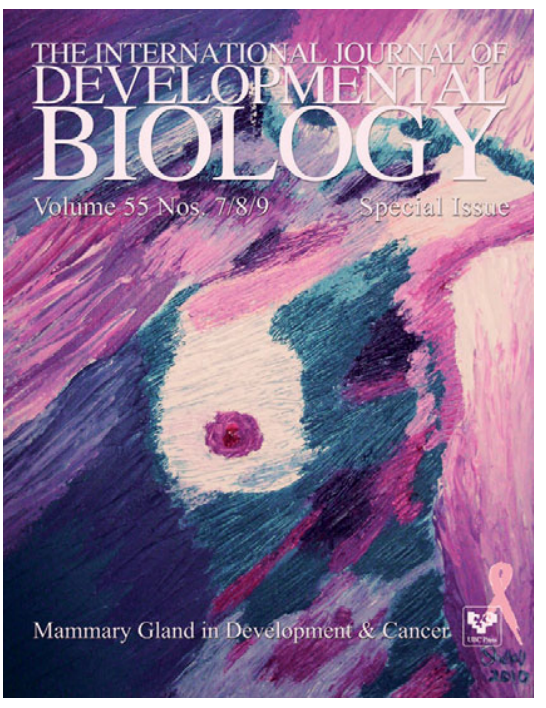

THE INTERNATIONAL JOURNAL OF DEVELOPNENTAI D) 000

Volume 55 Nos. $4 / 5$

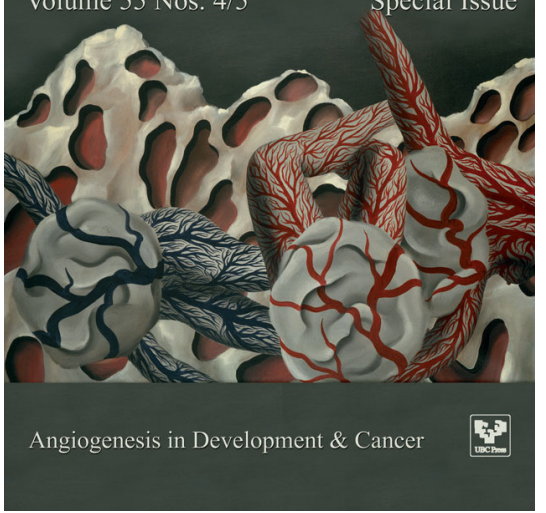

